\title{
Peremajaan Kawasan Pasar Kiaracondong Berkonsep Pasar Sehat
}

\section{Fahri Nazarudin*, Sri Hidayati Djoeffan}

Program Studi Perencanaan Wilayah dan Kota, Fakultas Teknik, Universitas Islam Bandung, Indonesia

*fahrinazarudin0405@gmail.com, sri.hidayati@unisba.ac.id

\begin{abstract}
The market is an economic sector that can improve people's welfare and be used by Governments as a wheel of economy. Traditional market nowadays existence aside from the existence of modern market, Kiaracondong Market has a pontesi as a first class market, trader as much as 1058 and has easy access. However, there are problems in terms of visual, environmental and functional. To fix the problem there is a rejuvenation need to be done. The purpose of this research is to rejuvenate the traditional market area of Kiaracondong to be comfortable, safe, clean healthy and sustainable. The method used is a theoretical, normative, comparative, participatory, and description-statistical approach. By using site analysis, population, land support, space needs, building typology, building period, City rejuvenation strategy and the determination of functional elements. Thus obtained the direction of design concept based on the results of analysis that has been done in the form of land use plan, period building, circulation and parking, green open space, pedestrian path, support activities, utility networks and Recommendations.
\end{abstract}

\section{Keywords: Area, Healthy Markets, Rejuvenation}

Abstrak. Pasar merupakan sektor perekonomian yang dapat meningkatkan kesejahteraan masyarakat dan digunakan oleh pemerintah sebagai roda perekonomian. Pasar tradisional saat ini keberadaannya tersisihkan adanya pasar modern, pasar kiaracondong memiliki pontesi sebagai pasar kelas satu, pedagang sebanyak 1058 dan memiliki akses yang mudah. Namun, terdapat permasalahan dari segi visual, lingkungan dan fungsional. Untuk memperbaiki permasalahan yang ada maka perlu dilakukan peremajaan. Tujuan dari penelitian ini ialah meremajakan kawasan pasar tradisional kiaracondong agar nyaman, aman, bersih sehat dan berkelanjutan. Metode yang digunakan berupa pendekatan teoritis, normatif, komparatif, partisipatif dan statistik deskripsi. Dengan menggunakan analisis tapak, kependudukan, daya dukung lahan, kebutuhan ruang, tipologi bangunan, tata masa bangunan, stategi peremajaan kota dan penentuan elemen fungsional. Sehingga diperoleh arahan konsep perancangan berdasarkan hasil analisis yang telah dilakukan berupa rencana tata guna lahan, tata masa bangunan, sirkulasi dan parkir, ruang terbuka hijau, jalur pejalan kaki, aktivitas pendukung, jaringan utilitas dan rekomendasi.

Kata Kunci: Kawasan, Pasar Sehat, Peremajaan 


\section{A. Pendahuluan}

Berdasarkan RTRW Kota Bandung bahwa SWK Karees memiliki fungsi khusus sebagai sektor perdagangan yang salah satunya ialah Pasar Kiaracondong. Dalam RTRW sendiri menyebutkan bahwa Pasar Kiaracondong termasuk kedalam pasar yang perlu dibangun kembali. Terdapat empat pasar di Kota Bandung yang akan direvitaliasi yaitu pasar cihaurgeulis, pasar kiaracondong, pasar sederhana dan pasar astanaanyar. Selain itu, Pasar Kiaracondong termasuk kedalam zona kawasan prioritas untuk diremajakan.

Pasar kiaracondong merupakan pasar kelas satu dengan jumlah pedangan sebanyak 1058 jiwa yang melayani daerah sekitarnya diantaranya kelurahan kebun jayanti, babakn surabaya, babakan sari, binong kecamatan batununggal dan kebon gedang batununggal. Pasar Kiaracondong merupakan pasar eceran dengan skala pelayanan lingkungan. Pasar Kiaracondong sebagai motor penggerak roda perekonomian Kota Bandung yang saat ini tersisihkan akibat adanya pasar modern dan swalayan.

Berdasarkan hasil pengamatan bahwa pasar kiaracondong memliki beberapa permasalahan dari segi visual, lingkungan dan fungsional seperti sampah berserakan, tidak adanya tanaman penghija, kondisi bangunan semi permanen, kurangnya jaringan drainase, parkir pada bahu jalan, pedagang yang berjualan di area trotoar dan area parkir dan KBD melebihi batas $80 \%$. Kemudian jika dilihat dari dalam bangunan pun terlihat sangat kumuh seperti kurangnya ventilasi, kabel listrik yang semrawut, tidak ada pemisah sampah kering dan basah, saluran drainase yang terbuka, toilet yang kuuh, alat pemadam yang tidak tertata dan penataan pedagang yang bercampur antara kering, basah dan makanan saji.

Berdasarkan permasalahan tersebut untuk mengatasi permasalahan yang ada, maka diperlukan peremajaan kawasan pasar kiaracondong sehingga terciptanya kawasan yang nyaman, aman, bersih, sehat dan berkelanjutan. Tujuan dilakukan studi ini adalah meremajakan kawasan pasar tradisional kiaracondong agar nyaman, aman, bersih sehat dan berkelanjutan". Adapun manfaat daari hasil studi dapat menjadi masukan dan referensi bagi instansi terkait di Kota Bandung dalam mengembangkan Kawasan Pasar Kiaracondong.

\section{B. Landasan Teori}

\section{Definisi Pasar Sehat}

Pasar Sehat adalah kondisi pasar yang bersih, nyaman, aman dan sehat melalui kerjasama seluruh stakeholder terkait dalam menyediakan pangan yang aman dan bergizi bagi masyarakat (Kepmenkes No. 519/2008). Pasar sehat adalah tempat di mana setiap orang bekerja sama untuk mencapai visi yang disepakati untuk kesehatan dan keselamatan masyarakat pasar. Seperti kota sehat, pasar sehat adalah salah satu yang terus menciptakan dan meningkatkan pasar fisik dan lingkungan sosial dan menciptakan situasi di mana masyarakat pasar sendiri diberdayakan untuk mencapai potensi maksimumnya (WHO:2004).

\section{Tujuan Pasar Sehat}

Tujuan keseluruhan dari program pasar sehat adalah untuk meningkatkan kesehatan dan keselamatan anggota masyarakat di pasar pengaturan secara berkelanjutan. Kesehatan dan keselamatan dalam konteks ini mengacu pada kesejahteraan fisik, mental dan sosial dari masyarakat pasar yang ditetapkan. Lebih jelasnya pasar sehat bertujuan untuk:

1. Menciptakan lingkungan yang sehat, aman dan mendukung

2. Memastikan bahwa promosi kesehatan dan perlindungan kesehatan merupakan pusat dari semua praktik pasar

3. Memastikan semua pemangku kepentingan utama berpartisipasi aktif dalam proses jika diperlukan

4. Memperluas dampak kesehatan yang positif kepada masyarakat setempat dan sekitarnya. 


\section{Kriteria Pasar Sehat}

Secara umum diatur dalam Keputusan Kementrian Kesehatan Nomor 519 tentang pedoman penyelenggaraaan pasar sehat dalam mewujudkan pasar sehat terdapat beberapa kriteria diantaranya:

1. Zonasi (pemisahan kegiatan yang berbeda) di pasar sangat penting untuk melindungi makanan siap santap dan membatasi penyebaran zoonoses yang muncul.

2. Drainase yang baik berkontribusi dalam pendoman pembangunan pasar sehat.

3. Pasar yang sehat membutuhkan pengelolaan limbah yang tepat.

4. Pendekatan pengaturan yang sehat memerlukan komitmen dari semua pemangku kepentingan utama termasuk politisi, pihak berwenang, dan konsumen.

5. Makanan yang aman manfaat semua. Daging, unggas dan ikan harus disimpan dingin. Ikan hidup harus disimpan dalam air bersih yang aman

6. Kunci untuk makanan yang lebih aman - Jaga agar makanan matang tetap panas $\left(>60^{\circ}\right.$ C) sebelum melayani $\bullet$ tetap dingin makanan tahan lama (sebaiknya $<5^{\circ} \mathrm{C}$ )

7. Keamanan terhadap kebakaran yang berarti perencanaan yang kabel berbahaya, mengendalikan sumber energi dan menyediakan sumber daya pengendalian kebakaran.

8. Keamanan manusia adalah penting aspek dari pedoman pasar yang sehat.

9. Di pasar yang berwenang harus menyediakan akses yang aman ke pasar dan membatasi akses kendaraan dalam pasar

10. Pasar sehat memerlukan tepat Perencanaan, desain dan konstruksi

11. Untuk menentukan apakah pasar yang sehat program telah mencapai tujuannya, ada kebutuhan untuk merencanakan kepala untuk evaluasi program.

Teori The Urban Design Process (Hamid Shirvani)

Menurut Hamid Shirvani, dalam penyelidikan terhadap bentuk kota terdapat 8 elemen utama yang mempengaruhinya. Adapun elemen-elem tersebut antara lain:

1. Tata Guna Lahan

Tata Guna Lahan merupakan rancangan dua dimensi berupa denah peruntukan lahan sebuah kota. Ruang-ruang tiga dimensi (bangunan) akan dibangun di tempat-tempat sesuai dengan fungsi bangunan tersebut. Sebagai contoh, di dalam sebuah kawasan industri akan terdapat berbagai macam bangunan industri atau di dalam kawasan perekonomian akan terdapat berbagai macam pertokoan atau pula di dalam kawasan pemerintahan akan memiliki bangunan perkantoran pemerintah. Kebijaksanaan tata guna lahan juga membentuk hubungan antara sirkulasi/parkir dan kepadatan aktivitas/penggunaan individual.

2. Bentuk dan Massa Bangunan

Building form and massing dapat meliputi kualitas yang berkaitan dengan penampilan bangunan, yaitu ketinggian bangunan, kepejalan bangunan, KLB, KDB, garis sempadan bangunan, langgam, skala, material, tekstur, warna

3. Sirkulasi dan Perparkiran

Sirkulasi adalah elemen perancangan kota yang secara langsung dapat membentuk dan mengkontrol pola kegiatan kota, sebagaimana halnya dengan keberadaan sistem transportasi dari jalan publik, pedestrian way, dan tempat-tempat transit yang saling berhubungan akan membentuk pergerakan (suatu kegiatan membentuk karakter suatu daerah, tempat aktivitas dan lain sebagainya. Tempat parkir mempunyai pengaruh langsung pada suatu lingkungan yaitu pada kegiatan komersial di daerah perkotaan dan mempunyai pengaruh visual pada beberapa daerah perkotaan.

4. Ruang Terbuka

Berbicara tentang ruang terbuka (open space) selalu menyangkut lansekap. Elemen lansekap terdiri dari elem keras (hardscape seperti jalan, trotoar, bebatuan dan sebagainya) serta elemen lunak (softscape) berupa tanaman dan air.

5. Signage

Penandaan yang dimaksud adalah petunjuk arah jalan, rambu lalu lintas, media iklan, dan berbagai bentuk penandaan lain. 
6. Pendukung Kegiatan

Pendukung kegiatan adalah semua fungsi bangunan dan kegiatan-kegiatan yang mendukung ruang publik suatu kawasan kota. Bentuk activity support antara lain taman kota, taman rekreasi, pusat perbelanjaan, taman budaya, perpustakaan, pusat perkantoran, kawasan PKL dan pedestrian, dan sebagainya.

7. Preservasi

Preservasi dalam perancangan kota adalah perlindungan terhadap lingkungan tempat tinggal (permukiman) dan urban places (alun-alun, plasa, area perbelanjaan) yang ada dan mempunyai ciri khas seperti halnya perlindungan terhadap bangunan bersejarah.

\section{Metode Penelitian}

Metode yang digunakan adalah metode kuantitatif dan kualitatif. Metode kualitatif adalah metode yang lebih menekankan pada aspek pemahaman secara mendalam terhadap suatu masalah daripada melihat permasalahan untuk penelitian generalisasi sedangkan Metode pendekatan kuantitatif adalah metode yang lebih menekankan pada aspek pengukuran secara obyektif terhadap fenomena sosial. Setalah penentuan metode maka dilakukan beberapa analisis diantaranya:

1. Analisis tapak dilakukan untuk mendapatkan/mengetahui daerah yang potensial untuk dikembangkan bagi kegiatan manusia. Skematika analisis tapak merupakan superimpose (tumpang tindih) dari potensi dan masalah berdasarkan variabel yang mempengaruhi yaitu: topografi, kemiringan, jenis tanah, hidrologi, geologi, vegetasi, iklim, dan tata guna lahan.

2. Analisis Kependudukan dibuat dengan tujuan untuk memprediksi jumlah penduduk masa yang akan datang. Untuk mengetahui jenis skala pelayanan pasar apakah akan berubah atau tetap di masa yang akan datang.

3. Analisis daya dukung lahan untuk mengetahui luasan lahan yang layak bangun (Potensial) dan lahan tidak layak bangun (limitasi).

4. Analisis kebutuhan ruang dibuat dengan tujuan untuk mengetahui seberapa besar luas lahan yang dibutuhkan oleh kelompok-kelompok aktivitas yang direncanakan agar dapat berfungsi dan berjalan dengan baik, sehingga tercipta keberlangsungan aktivitas di kawasan perancangan

5. Analisis tipologi bangunan yaitu merumuskan ukuran, bentuk (tipologi) untuk perancangan sehingga tipologi bangunan yang dihasilkan sesuai standar.

6. Analisis tata masa bangunan membahas mengenai Koefisien Dasar Bangunan (KDB), Koefisien Lantai Bangunan (KLB), jarak antar bangunan dan luas lantai terbangun dari keadaan eksisting hingga rencana.

7. Analisis strategi peremajaan kota bertujuan untuk perbaikan dan perlindungan lingkungan, peningkatan kehidupan masyarakat setempat dan pemenuhan standar kelayakan.

8. Analisis penentuan fungsional bertujuan untuk melihat kebutuhan dalam memenuhi konsep yang sesuai dengan kebijakan dan teori.

\section{Hasil Penelitian dan Pembahasan}

\section{Analisis Tapak}

Berdasarkan hasil skoring dari total luas kawasan studi \pm 6906 Ha diperoleh hasil bahwa seluruh kawasan studi merupakan kawasan yang layak dibangun.

\section{Analisis Daya Dukung Lahan}

perhitungan daya dukung lahan adalah sebagai berikut :

$$
\text { Daya Dukung }=\text { Luas Wilayah }- \text { Daerah }
$$


Luas Wilayah : $6.906 \mathrm{~m}^{2}$

Daerah Limitasi : $0 \mathrm{~m}^{2}$

Sehingga dari rumus di atas maka dapat disimpulkan bahwa daya dukung lahan Pasar Kiaracondong yaitu $6.906 \mathrm{~m}^{2}$ dan tidak terdapat daerah limitasi.

\section{Analisis Kependudukan}

Untuk analisis kependudukan mengunakan analisis eskponensial kecenderungan dengan pertambahan penduduk meningkat tiap tahunnya (konstan). Berdasarkan data kependudukan skala lingkungan pasar kiaraconsong bahwa laju pertumbuhan penduduk sebesar 0,008\% pertahunnya. hasil analisis proyeksi diatas bahwa pada tahun 2038 (20 tahun) mendatang Pasar Kiaracondong bertambah 1.599 jiwa, sehingga jumlah penduduk berjumlah menjadi 100.698 jiwa. Sehingga Peremajaan Pasar Kiaracondong memiliki skala pelayanan lingkungan untuk melayani 100.698 jiwa pada Tahun 2038.

\section{Analisis Kebutuhan Ruang Tahun 2038}

1. Kebutuhan Ruang Terbangun (Penggunaan Lahan Utama)

Berikut kebutuhan kios dan lapak Pasar Kiaracondong dapat dilihat pada Tabel 1

Tabel 1. Kebutuhan Ruang Terbangun Tahun 2038

\begin{tabular}{|c|c|c|c|c|c|}
\hline No & Jenis Bangunan & $\begin{array}{c}\text { Jumlah } \\
\text { Eksisiting } \\
\text { (Unit) }\end{array}$ & $\begin{array}{c}\text { Jumlah } \\
\text { Rencana } \\
\text { (Unit) }\end{array}$ & Ukuran $\left(\mathbf{m}^{2}\right)$ & $\begin{array}{c}\text { Luas } \\
\left(\mathbf{m}^{2}\right)\end{array}$ \\
\hline 1 & Lapak & 400 & 288 & $1,5 \times 1,5$ & 648 \\
\hline 2 & Kios & 346 & 159 & $3 \times 4$ & 1.872 \\
\hline 3 & Mushola & 2 & 1 & $10 \times 10$ & 100 \\
\hline 4 & Kantor Pengelola & 1 & 1 & $8 \times 8$ & 64 \\
\hline 5 & Pos Kesehatan & - & 1 & $5 \times 4$ & 20 \\
\hline 6 & Pos Keamanan & - & 1 & $3 \times 5$ & 15 \\
\hline 7 & Tempat Futsal & 1 & 1 & $15 \times 25$ & 375 \\
\hline 8 & Foodcourt & - & 1 & $12 \times 30$ & 360 \\
\hline 9 & Toko obat & - & 1 & $4 \times 6$ & 24 \\
\hline 10 & ATM bersama & - & 1 & $10 \times 3$ & 30 \\
\hline 11 & Gudang & - & 1 & $8 \times 8$ & 64 \\
\hline \multicolumn{5}{|c|}{ Jumlah } & 3.572 \\
\hline
\end{tabular}

Sumber: Hasil Analisis, 2019

2. Kebutuhan Ruang Terbuka Hijau

Berdasarkan RDTR SWK Karees Tahun 2011-2031 menyebutkan bahwa kebutuhan ruang terbuka hijau untuk kawasan perdagangan dan jasa yaitu sebesar 5-20\%. Sehingga berdasarkan hasil perhitungan di atas didapatkan bahwa kebutuhan ruang terbuka hijau di Pasar Kiaracondong yaitu 345,3 $\mathrm{m}^{2}-1.381,2 \mathrm{~m}^{2}$

3. Kebutuhan Ruang Parkir

Merujuk kepada Ketetapan Direktorat Jendral Perhubungan Darat No. 272/HK.105/DRJD/96 Tentang Pedoman Teknis Penyelenggaraan Fasilitas Parkir bahwa satuan ruang parkir mobil berdimensi $2,5 \mathrm{~m}$ x $5 \mathrm{~m}$ dan motor $0,75 \mathrm{~m} \times 2 \mathrm{~m}$. kemudian dibagi dengan luas tapak dan kios yang telah direncanakan dan didapat hasil 26 satuan ruang parkir monil sedangkan untuk motor dua kali dari satuan rung parkir mobil, yaitu 52.

4. Kebutuhan Ruang Toilet

Untuk penyediaan toilet mengikuti standar Keputusan Menteri Kesehatan Nomor 519 Tentang Pedoman Penyelenggaraan Pasar Sehat dapat dilihat pada Tabel 3 
Tabel 2. Standar Toilet Umum

\begin{tabular}{|c|c|c|c|}
\hline No & Jumlah Pedagang & $\begin{array}{c}\text { Jumlah kamar } \\
\text { mandi }\end{array}$ & Jumlah Toilet \\
\hline 1 & s/d 25 & 1 & 1 \\
\hline 2 & 25 s/d 50 & 2 & 2 \\
\hline 3 & 51 s/d 100 & 3 & 3 \\
\hline \multicolumn{2}{|r|}{ Setiap penambahan 40-100 orang harus ditambah satu kamar mandi dan satu toilet } \\
\hline
\end{tabular}

Sumber: Kemenkes No.519 toilet.

Berdasarkan stardar diatas bahwa didapatkan bahwa setiap lantai pasar terdapat enam

5. Kebutuhan Ruang TPS

Jika melihat SNI 19-3983-1995 Tentang Spesifikasi Timbulan Sampah Untuk Perkotaan di Indonesia bahwa timbulan sampah di pasar yaitu 0,60 liter $/ \mathrm{m}^{2} / \mathrm{hari}$. Maka didapatkan timbulan sampah sebagaimana pada Tabel 3. Berdasarkan jumlah timbulan sampah yang didapat, maka kebutuhan ruang TPS di Pasar Kiaracondong termasuk kedalam klasifikasi TPS Tipe I dengan luas $50 \mathrm{~m} 2$ dengan volume timbulan sampah hingga $100 \mathrm{~m} 3$.

\section{Kebutuhan tipologi Bangunan}

1. Tipologi Banguna Pasar Modern

Di dalam perancangan tipologi bangunan pasar modern akan dirancang menjadi lima zona yaitu zona perdagangan pangan basah, zona perdagangan pangan kering, zona perdagangan makanan siap saji, zona perdagangan non pangan dengan menggunakan lapak dan kios dan zona non perdagangan. Tipologi bangunan Pasar akan berukuran 45 x 47 meter dengan jumlah 4 lantai.

2. Tipologi Bangunan Gedung Parkir

Di dalam perancangan Pasar Kiaracondong akan dibangun sebuah gedung parkir untuk mobil dan motor. Tipologi bangunan gedung parkir akan berukuran 26 x 30 dengan jumlah 2 lantai

Tabel 3. Perhitungan Timbulan Sampah Pasar Kiaracondong

\begin{tabular}{|c|c|l|l|c|l|c|}
\hline No & $\begin{array}{c}\text { Komponen } \\
\text { Sumber } \\
\text { Sampah }\end{array}$ & Sumber Sampah & Satuan & $\begin{array}{c}\text { Volume } \\
\text { (liter) }\end{array}$ & Keterangan & $\begin{array}{c}\text { Jumlah Timbulan } \\
\text { Sampah }\end{array}$ \\
\hline 1 & Pasar & $\begin{array}{l}\text { Pasar Modern } \\
\text { Kiaracondong }\end{array}$ & $/ \mathrm{m}^{2} / \mathrm{hari}$ & 0,60 & $\begin{array}{l}\text { Luas rencana } \\
\text { Pasar Modern } \\
\text { Kiaracondong } \\
\text { yaitu 3.107,7 } \mathrm{m}^{2}\end{array}$ & $\begin{array}{c}3.107,7 \times 0,60= \\
1.864,62 \text { liter } / \text { hari }\end{array}$ \\
\hline \multicolumn{5}{|c|}{ Total Timbulan Sampah } & $\begin{array}{c}1.864,62 \text { liter } / \mathrm{hari} \\
\text { atau } 1,86 \mathrm{~m}^{3} / \mathrm{hari}^{2}\end{array}$ \\
\hline
\end{tabular}

Sumber : Hasil Analisis, 2019

3. Tipologi Bangunan Mushola

Dilihat dari SNI 03-1733-2004 Tentang Tata Cara Perencanaan Lingkungan Perumahan

Di Perkotaan bahwa Pasar Kiaracondong masuk kedalam kategori musholah dengan luas lahan minimal $45 \mathrm{~m}^{2}$.

4. Tipologi Tempat Pembuangan Sampah

Menurut hasil analisis kebutuhan ruang TPS, Pasar Kiaracondong masuk kedalam kategori TPS Tipe 1 dengan ukuran $50 \mathrm{~m}^{2}$

5. Tipologi Kantor Pengelolaan Pasar

Untuk bangunan Kantor Pengelola Pasar Kiaracondong eksisting memiliki ukuran $64 \mathrm{~m}^{2}$ 
6. Tipologi Lapangan Futsal

Untuk lapangan Futsal Kiaracondong eksisting memiliki ukuran $204 \mathrm{~m}^{2}$ sehingga akan direncanakan bangunan kantor seluas $204 \mathrm{~m}^{2}$

7. Tipologi Foodcourt

Untuk ukuran foodcourt disesuaikan dengan luas rencana yang kosong.

\section{Analisis Tata Masa Bangunan}

Sementara, untuk rencana berdasarkan RDTR SWK Karees Tahun 2011-2031 menyebutkan bahwa Pasar Kiaracondong yang terletak di Jalan Kolektor termasuk kedalam fungsi eceran aglomerasi (pusat belanja/mall) dengan ketentuan KDB maksimal 60\%, dan KLB 1,8. Berikut perhitungan tersebut.

$$
\begin{array}{ll}
\text { luas lantai terbangun } & =\text { KDB X luas total lahan } \\
& =60 / 100 \times 6.906 \mathrm{~m}^{\wedge} 2=4.143,6 \mathrm{~m}^{2} \\
\text { luas lantai yang boleh dibangun } & =\text { KLB X luas lantai terbangun } \\
& =1,8 \times 4.143,6 \mathrm{~m}^{\wedge} 2=7.458,48 \mathrm{~m}^{2} \\
& =(\text { total lantai terbangun }) /(\text { luas lantai terbangun }) \\
\text { jumlah lantai } & =\left(7.458,48 \mathrm{~m}^{2}\right) /\left(4.143,6 \mathrm{~m}^{2}\right)=1,8 \cong 2 \text { lantai }
\end{array}
$$

\section{Analisis peremjaan kota}

Untuk Kawasan Pasar Kiaracondong setelah diidentfkasi dan dianalisis maka menghasilkan strategi peremajaan yaitu redevelopment atau rekontruksi dan konservasi

\section{Analisis elemen fungsional}

Untuk Kawasan Pasar Kiaracondong ini berpedoman kepada Keputusan Menteri Keseharan No. 519 Tahun 2008 Tentang Pedoman Penyelenggaraan Pasar Sehat dan dikaitkan dengan hasil perancangan yang berpedoman Teori The Urban Design Process (Hamid Shirvani)

\section{Produk Perencanaan}

Dalam penelitian ini diperoleh hasil perancangan kawasan yang mengacu pada teori elemen pembentuk kota Hamid Sirvani. Hasil perancangan secara keseluruhan sudah terintegrasi dari satu elemen ke elemen lainnya, mulai dari penggunaan lahan, sirkulasi dan perparkiran, ruang terbuka, tata masa bangunan, aktivitas pendukung, penandaan, preservasi, dan kalur pejalan kaki. Untuk lebih jelasnya dapat dilihat pada Gambar 5.1 (kondisi eksisting sebelum dan sesudan dirancang)

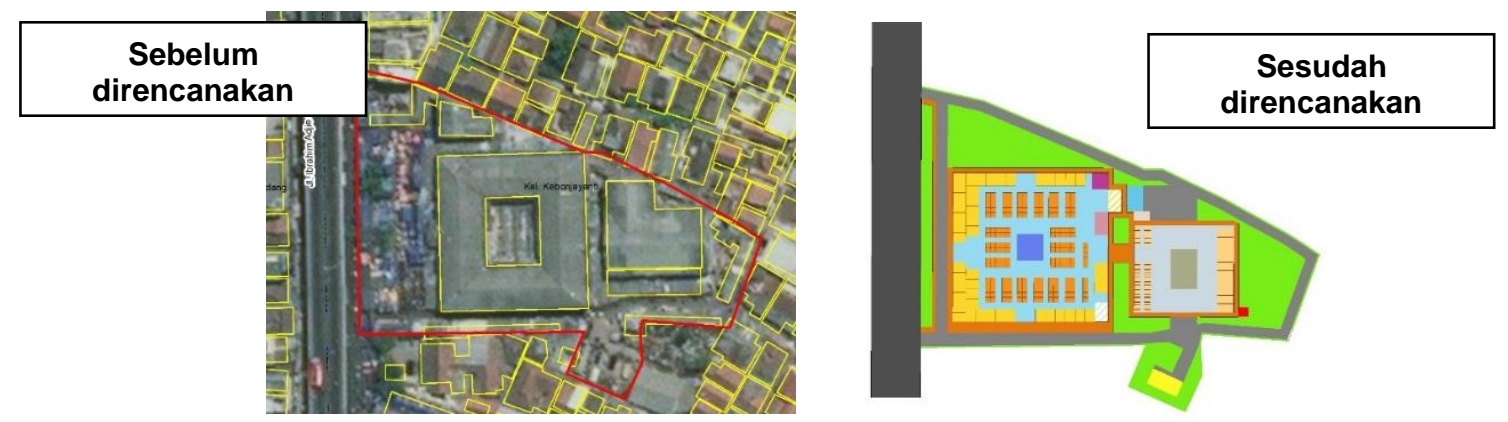

Gambar 2. kondisi eksisting sebelum dan sesudan dirancang

Sumber : Hasil Perancangan, 2019 


\section{Daftar Pustaka}

De Chiara, Joseph, and John Callender, (1980). Time Saver Standaed for Building Types, Mc Graw Hill, New York

Shirvani, Hamid. (1985). The Urban Design Process. Van Nostrand Reinhold. New York.

Engineer Weekly, (2016), Teknologi Bangunan Hijau. (Nomor 3 W. III April 2016)

Bakri, M. Strategi Peningkatan Posisi Tawar Pasar Tradisional Terhadap Pedagang Di Kota Bogor (Tugas Akhir) Bogor. Sekolah Pasca Sarjana. Institut Pertanian Bogor.

Zahrul B. (2014). Penataan Kawasan Pasar Tradisional Kenanga-Anggrek. Universitas Tanjungpura, Pontianak

Oktavina, Galuh. (2011). Redesain Pasar Tradisional Jongke, Surakarta. Yogyakarta. Universitas Atma Jaya Yogyakarta

Zuliana E. 2016. "Revitalisasi Pasar Tradisional Ngemlak Tulungagung” Universitas Islam Negeri Maulana Malik Ibrahim. Malang.

Ziliwu O. Dkk. (2017) "Penentuan Skala Pelayanan Pada Kawasan Perdaganagan Bagian Kota Malang Barat" urusan Perencanaan Wilayah dan Kota, Fakultas Teknik Sipil dan Perencanaan, Institut Teknologi Nasional Malang (ITN)

Keputusan Menteri Kesehatan Nomor 519 Tahun 2008 Tentang Pedoman Penyelenggaraan Pasar Sehat

Peraturan Daerah Kota Bandung Nomor 3 Tahun 2014 Tentang Rencana Pembangunan Jangka Menengah Daerah Tahun 2013 - 2018

Peraturan Daerah Kota Bandung Nomor 20 Tahun 2001 Tentang Retribusi Pasar

Peraturan Kota Bandung No.19 Tahun 2001 Tentang Pengelolaan Pasar di Kota Bandung

Peratuan Daerah Kota Bandung Nomor 18 Tahun 2011 Tentang Rencana Tata Ruang Wilayah Kota Bandung Tahun 2011-2031

Peraturan Wali Kota Bandung Nomor 809 Tahun 2018 Tentang Prosedur Dan Mekanisme Pelaksanaan Teknik Pengaturan Zonasi Melalui Penerapan Pengalihan Hak Membangun 